\title{
The current status of autotitrating continuous positive airway pressure systems in the management of obstructive sleep apnea
}

\author{
David Hailey $\mathrm{PhD}^{1}$, Philip Jacobs $\mathrm{PhD}^{1}$, Irvin Mayers MD², Shaila Mensinkai MLIS ${ }^{3}$
}

\begin{abstract}
D Hailey, P Jacobs, I Mayers, S Mensinkai. The current status of autotitrating continuous positive airway pressure systems in the management of obstructive sleep apnea. Can Respir J $2005 ; 12(5): 271-276$.
\end{abstract}

BACKGROUND: Autotitrating continuous positive airway pressure (APAP) devices have the potential to address some of the disadvantages of titration and treatment with conventional continuous positive airway pressure (CPAP). Information on the performance of APAP in clinical use is still comparatively limited.

OBJECTIVE: To assess the status of APAP devices in the management of obstructive sleep apnea (OSA) by reviewing evidence of their efficacy, effectiveness and costs.

METHODS: A systematic search of electronic databases and a review of selected comparative studies on the use of APAP in the diagnosis, titration and treatment of OSA was undertaken. Cost analysis using data applicable to the management of OSA in Edmonton, Alberta was performed.

RESULTS: Thirty-three studies met the selection criteria: three on the use of APAP in diagnosing OSA; six on APAP for titration; 14 that considered short-term treatment outcomes; and 10 that addressed longer-term treatment of OSA. In most studies, patients suffering from cardiac, pulmonary and other medical conditions were excluded. Available data suggested some potential for the use of APAP in the diagnosis of OSA, but further validation is needed. In titration, estimated treatment pressures tended to be lower with APAP than with the manual titration of CPAP. Although lower treatment pressures were achieved with APAP, there was no significant difference in clinical outcome measures between APAP and CPAP. Estimates of costs suggested that APAP may provide savings in some scenarios.

CONCLUSIONS: APAP shows promise in the management of OSA; however, given the exclusion of some categories of patients from trials of this technology, caution is still required in its use.

Key Words: Autotitrating CPAP; Continuous positive airway pressure; Cost analysis; Diagnosis; Obstructive; Sleep apnea; Titration; Treatment outcomes

$\mathrm{N}$ asal continuous positive airway pressure (CPAP) is a wellestablished treatment for moderate-to-severe obstructive sleep apnea (OSA), and has been shown to reduce both subjective and objective measures of daytime sleepiness in randomized placebo-controlled trials (1).

Autotitrating CPAP (APAP) devices have been developed in which the positive pressure level applied to the patient through the mask changes during sleep, taking into account the disappearance and reappearance of apnea and hypopnea and other physiological events. These other events may include an index of mask vibration (snoring), indexes of

\section{Statut actuel des systèmes d'ajustement automatique de la pression positive continue dans la prise en charge de l'apnée obstructive du sommeil}

HISTORIQUE : Les dispositifs d'ajustement automatique de la pression positive continue (AAPPC) pourraient remédier à certains inconvénients liés et au traitement général au moyen des appareils standard de pression positive continue (PPC) et à leur ajustement. L'information sur le rendement des systèmes d'AAPPC en clinique demeure cependant limitée en comparaison.

OBJECTIF : Évaluer le statut des systèmes d'AAPPC dans la prise en charge de l'apnée obstructive du sommeil (AOS) en analysant leurs effets cliniques et leur coût.

MÉTHODES : Une interrogation systématique des bases de données électroniques et une revue de certaines études comparatives sélectionnées sur l'utilisation de l'AAPPC pour le diagnostic, le traitement de l'AOS et son ajustement ont été entreprises. Une analyse des coûts a été menée à l'aide de données relatives au traitement de l'AOS à Edmonton, Alberta. RÉSULTATS : Trente-trois études répondaient aux critères de sélection : trois sur l'utilisation de l'AAPPC pour le diagnostic de l'AOS, six sur l'ajustement du traitement, 14 sur l'issue thérapeutique à court terme et 10 sur l'issue thérapeutique à long terme. Dans la plupart des études, les patients présentant des problèmes de santé cardiaques, pulmonaires et autres ont été exclus. Les données disponibles donnent à penser que l'AAPPC serait utile pour le diagnostic de l'AOS, mais une validation plus approfondie s'impose. Sur le plan de l'ajustement du traitement, les pressions thérapeutiques estimées avaient tendance à être plus faibles avec l'AAPPC qu'avec l'ajustement manuel de la PPC. Bien que des pressions thérapeutiques plus basses aient été enregistrées avec l'AAPPC, aucune différence significative n'a été enregistrée pour ce qui est de l'issue clinique entre l'AAPPC et le traitement de PPC standard. Les estimations des coûts donnent à penser que l'AAPPC pourrait se révéler économique dans certains cas.

CONCLUSION : L'AAPPC est prometteuse pour la prise en charge de l'AOS. Par contre, le fait que certaines catégories de patients aient été exclues des essais sur cette technologie impose la prudence quant à son emploi.

flow limitation (including flattening) and indexes of airway patency (including detection of cardiac oscillation). Such devices have the potential to address some of the disadvantages of attended titration and treatment with conventional CPAP. These include the resource-intensive nature of manual titration, the inability to obtain treatment pressure in some patients if a 'split-night' approach is used and the possibility of the fixed-pressure value being higher than needed for the entire night, with a possible increase in mask leaks and pressure intolerance, and imperfect compliance with CPAP treatment.

\footnotetext{
Departments of ${ }^{1}$ Public Health Sciences and ${ }^{2}$ Medicine, University of Alberta, Edmonton, Alberta; ${ }^{3}$ Canadian Coordinating Office for Health Technology Assessment, Ottawa, Ontario

Correspondence: Dr David Hailey, 22 Sinclair Street, Kambah, ACT 2902, Australia. Telephone 61-26-231-6539, fax 61-26-231-1090,

e-mail dhailey@ozemail.com.au
} 
TABLE 1

Details of selected studies on autotitrating continuous positive airway pressure

\begin{tabular}{lcc}
\hline Application & Number of studies & Study design \\
\hline Diagnosis of OSA & 3 & All NRC \\
Titration & 6 & $1 \times$ RCT \\
& & $2 \times$ RCT-C \\
& 14 & $1 \times$ NRC \\
Short-term treatment of OSA & $10 \times$ RCT-C \\
& & $3 \times$ NRC \\
Longer-term treatment of OSA & 10 & $5 \times$ RCT \\
& & $5 \times$ RCT-C \\
\hline
\end{tabular}

NRC Nonrandomized prospective comparative study; OSA Obstructive sleep apnea; RCT Randomized controlled trial; RCT-C Randomized crossover study

The availability of APAP devices offers the potential to change the way moderate-to-severe OSA is managed. The use of this technology could alter the way that sleep laboratories are operated and permit some investigations to be conducted outside a laboratory setting. In addition, APAP offers a possible alternative to the conventional treatment of OSA with CPAP. There is particular interest in providing diagnostic services to individuals with sleep disorders in their own homes, without necessarily any contact with sleep laboratories or other specialized services.

We undertook an assessment of the current status of APAP to assist decision makers who are involved in the management of individuals with OSA. We reviewed the evidence from comparative studies on the efficacy (performance under optimum conditions), effectiveness (performance in routine use) and costs of APAP devices in three following applications: the diagnosis of OSA; titration to determine CPAP pressure values; and ongoing treatment of OSA using variable pressure mode.

\section{METHODS}

The MEDLINE, EMBASE, BIOSIS Previews, PASCAL, INSPEC and F-D-C Reports databases were searched from 1994 to April 2003. The search was conducted using MeSH headings, subject headings, text words, key words, device names, product names and appropriate operators to capture relevant studies, with no language restrictions. The Cochrane Library and Cumulative Index to Nursing \& Allied Health Literature database were searched separately. The search strategy is available from the authors. Reference lists of relevant articles were checked to identify additional studies.

Selected studies included comparative studies with APAP for individuals with OSA who may have required CPAP treatment. For the diagnosis of OSA and titration, comparisons were made using polysomnography in a laboratory. For the treatment of OSA, comparisons were made with conventional fixed-pressure CPAP. The outcomes considered for the use of APAP in the diagnosis of OSA were the accuracy of the diagnosis, costs and identification of adverse conditions, all in comparison with sleep laboratory studies using polysomnography. For titration, primary outcomes of interest were estimations of the accuracy of final pressure settings, identification of adverse conditions and costs in comparison with sleep laboratory studies. For therapeutic use of APAP in variable pressure mode, the outcomes considered were compliance with treatment, effects on sleep patterns, other relevant physiological measures, quality of life and costs in comparison with treatment using conventional fixed-pressure CPAP.
Independent reviews of all citation titles and abstracts retrieved (to make inclusion decisions for subsequent full-text review) were undertaken by two of the authors (DH and PJ). The selected articles were independently reviewed by the same authors and accepted for assessment if they met the selection criteria. Any differences were resolved by consensus. Duplicate publications of the same trial were excluded, with the most recent and/or informative article being selected. All selection decisions for abstracts and retrieved papers were discussed with a third author (IM). Data from selected studies were independently extracted by the three authors.

To provide further information on cost issues associated with APAP, an analysis was undertaken using data on the use of APAP and CPAP that were applicable to the management of OSA in Edmonton, Alberta. In the present analysis, a five-year time horizon was used, which is the approximate lifetime of a positive airway pressure machine. All diagnostic, treatment and equipment (CPAP and APAP) costs were assumed to occur in the first year.

\section{RESULTS}

The authors identified 312 potentially relevant abstracts and selected 61 reports for further review. Of these, 39 reports describing 38 studies on APAP were selected for analysis. There were three studies on the use of APAP in the diagnosis of OSA, six on APAP for titration, 14 that considered shortterm treatment outcomes (single-night comparisons) and 10 that addressed longer-term treatment. Details of the study designs used are shown in Table 1. Three studies that considered noncomparative approaches to appraisal of titration were included in the analysis to provide further background on this technology.

The majority of patients studied were individuals who had been diagnosed with severe OSA. Criteria for their inclusion commonly included minimum values for body mass index and the apnea-hypopnea index (AHI). Some studies also included patients with other types of sleep-related breathing disorders. In many studies, patients with congestive heart failure or chronic lung disease were excluded. None of the studies included patients with a substantial amount of central apnea at baseline.

\section{Diagnosis}

The three studies (2-4) examining APAP for the diagnosis of OSA all used versions of the AutoSet device (ResMed, Australia). In each study, a simultaneous comparison with fullnight polysomnography was performed in an attended setting. Based on data from 11 patients, Huang et al (2) found a sensitivity of $70 \%$ and a specificity of $100 \%$. In a larger series, Gugger (3) reported a sensitivity of $97 \%$ and a specificity of $77 \%$ for the diagnosis of patients who had an AHI of more than 20 episodes of apnea per hour. A previous study by Gugger et al (4), using an earlier version of the AutoSet device that only detected episodes of apnea, gave a sensitivity of $82 \%$ and a specificity of $90 \%$ for the diagnosis of OSA based on episodes of apnea (again, more than 20 episodes of apnea per hour). None of these studies specifically considered interventions based on the diagnostic findings.

\section{Titration}

The six studies (5-11) that compared APAP titration with manual titration primarily focused on treatment pressures obtained using the two approaches on successive nights. A randomized controlled trial and two randomized crossover studies found no significant difference between pressures derived from 
TABLE 2

Longer-term studies of treatment using autotitrating continuous positive airway pressure (APAP)

\begin{tabular}{|c|c|c|c|c|c|c|c|c|c|}
\hline Study (reference) & APAP device & $\begin{array}{l}\text { udy period } \\
\text { (days) }\end{array}$ & $\begin{array}{l}\text { Difference in } \\
\text { treatment pressure }\end{array}$ & AHI & $\begin{array}{l}\text { ESS, daytime } \\
\text { sleepiness }\end{array}$ & $\begin{array}{c}\text { MWT, } \\
\text { arousals }\end{array}$ & $\begin{array}{c}\text { Sleep } \\
\text { architecture }\end{array}$ & $\begin{array}{c}\text { Use of } \\
\text { apparatus }\end{array}$ & $\begin{array}{c}\text { Patient } \\
\text { preference }\end{array}$ \\
\hline Planès et al, 2003 (29) & REM + auto* & 60 & - & NS & NS & - & NS & - & NS \\
\hline Massie et al, $2003(30)$ & AutoSet $^{\dagger}$ & 84 & APAP $<$ CPAP & - & NS & - & - & APAP $>$ CPAP & APAP $>$ CPAP \\
\hline Randerath et al, 2001 (31) & Somnosmart ${ }^{\ddagger}$ & 84 & APAP $<$ CPAP & NS & NS & NS & NS & NS & APAP $>$ CPAP \\
\hline d'Ortho et al, 2000 (33) & REM + auto & 30 & APAP $<$ CPAP & NS & NS & NS & NS & NS & APAP $>$ CPAP \\
\hline Hudgel and Fung, 2000 (34) & Virtuoso Smart - CPAP§ & $\S 84$ & APAP $<$ CPAP & - & NS & - & - & APAP $>$ CPAP & - \\
\hline Teschler et al, 2000 (35) & AutoSet & 60 & APAP $<$ CPAP & NS & - & - & - & NS & - \\
\hline Konermann et al, 1998 (36) & Horizon $\pi$ & $90-180$ & APAP $<$ CPAP & NS & - & - & NS & APAP $>$ CPAP & - \\
\hline Sériès and Marc, 1997 (14) & Morphée Plus** & 21 & APAP $<$ CPAP & NS & - & NS & - & NS & - \\
\hline Meurice et al, 1996 (37) & Morphée Plus & 21 & - & NS & NS & - & - & APAP $>$ CPAP & - \\
\hline
\end{tabular}

${ }^{*}$ Nellcor Puritan Bennett, France; †ResMed, Australia; ¥Weinmann, Germany; §Respironics, USA; TDeVilbiss, Germany; **Laboratoire Pierre Médical, France. AHI Apneahypopnea index; CPAP Continuous positive airway pressure; ESS Epworth Sleepiness Scale; MWT Maintenance of wakefulness test; NS Not statistically significant; REM Rapid eye movement

APAP and those from manual titration. In three nonrandomized comparisons, established pressures using APAP were significantly lower than those from manual titration. Titration was unattended in one study (8) and attended in the others.

Three studies (12-14) used noncomparative approaches to evaluate APAP titration, with outcomes being assessed following the establishment of a pressure value. In a small series reported by Berkani et al (12), eight of 10 patients had an AHI of less than 10 apnea episodes per hour after CPAP treatment for two weeks following unattended APAP titration in a hospital. In a study reported by Sériès (13), a pressure value estimated from a formula based on body mass index, neck circumference and AHI was used in home APAP titration to determine a value for effective treatment pressure, which was then used for a threeweek treatment with CPAP. The Epworth Sleepiness Scale (ESS), a questionnaire routinely used to assess excessive daytime sleepiness, was reduced significantly from baseline. An earlier study (14) that employed a similar approach showed that improvements in ESS after APAP treatment using the estimated reference pressure were similar to those for treatment using CPAP or APAP, with effective treatment pressure values defined by manual titration.

\section{Treatment}

Fourteen studies (15-28) included short-term measures of outcome, with one night of APAP compared with one night of CPAP. In 12 studies (15-24,26,28), there was a comparison of treatment pressures. APAP treatment produced significantly lower pressures than CPAP treatment in nine of the studies $(15-18,21-23,26,28)$, and there was no significant difference in two studies $(20,24)$. The remaining study (19) reported the maximum rather than the mean pressure for APAP, which was higher than that obtained with manual titration.

Treatment outcomes were similar for the two approaches. In 12 studies (15-23,26-28), there was no significant difference in AHI values, with scores for APAP being lower in four of the studies. In the other two studies $(24,25)$, values for APAP were significantly higher than those for CPAP. There was no significant difference in sleep architecture measures for eight of nine studies. In one study (27), there was a significantly higher stage 3 and 4 sleep for the group who received APAP. There was no significant difference in arousal index scores in 11 studies $(15-23,25,26,28)$ or for sleep time in three studies $(18,25,26)$.
Ten randomized studies (14,29-37) considered longer-term APAP treatment with measurements taken over periods from 21 to 180 days. One study (32) addressed the use of APAP in a subset of patients who had sleep stage- and body positiondependence related to their obstructive breathing abnormalities. In that group $(n=12)$, the ESS was significantly lower with APAP than with CPAP.

In the remaining nine studies (14,29-31,33-37), although there were differences in the equipment used and outcomes measured, overall results matched the measures obtained from the short-term investigations (Table 2). Treatment pressures were lower for APAP than for CPAP (statistically significant in seven of eight studies) but there was no significant difference for clinical measures including AHI (in seven of seven studies), daytime sleepiness (in six of six studies), arousals (in three of three studies) and sleep architecture (in three of three studies). In four of eight studies, patients used APAP more than CPAP; in four others, there was no significant difference.

In three of four studies that included surveys of patient preferences and opinion, APAP was preferred to CPAP. Massie et al (30) found that during APAP, patients reported more restful sleep, better quality sleep, less discomfort from pressure and less trouble getting to sleep. Randerath et al (31) reported that $75 \%$ of responders preferred APAP. In the study by d'Ortho et al (33), 15 responders (60\%) preferred APAP, eight preferred CPAP and two opted for surgery. Planes et al (29) reported that a large majority of patients in both a conventional CPAP group and an APAP group were satisfied with their treatment.

\section{Costs}

Only one study (29) was located that included comparative cost information. In that study, APAP treatment was started at home for one group of patients. Data on pressure levels and hours of APAP use were transmitted daily to a sleep laboratory and the pressure range for treatment set after one week. In the other group of patients, manual titration was carried out in a sleep laboratory using overnight polysomnography and the APAP device in constant-pressure mode. For treatment, the APAP device was used in variable-pressure mode for the group titrated at home, and in constant-pressure mode for the group titrated in the laboratory. 


\section{TABLE 3}

Costs for alternative hypothetical approaches to the management of sleep apnea

\begin{tabular}{|c|c|c|c|c|c|}
\hline $\begin{array}{l}\text { Resource } \\
\text { category }\end{array}$ & $\begin{array}{l}\text { Laboratory diagnosis } \\
\text { and titration, treatment } \\
\text { with CPAP (\$) }\end{array}$ & $\begin{array}{c}\text { Laboratory diagnosis } \\
\text { and titration, treatment } \\
\text { with APAP (\$) }\end{array}$ & $\begin{array}{l}\text { Laboratory diagnosis, } \\
\text { home titration with APAP, } \\
\text { treatment with CPAP (\$) }\end{array}$ & $\begin{array}{l}\text { Home diagnosis and } \\
\text { titration with APAP, } \\
\text { treatment with CPAP (\$) }\end{array}$ & $\begin{array}{c}\text { Home diagnosis and } \\
\text { titration with APAP, } \\
\text { treatment with APAP (\$) }\end{array}$ \\
\hline Diagnosis & $750^{*}$ & $750^{*}$ & $750^{*}$ & $200^{\dagger}$ & $200^{\dagger}$ \\
\hline Titration & $750^{*}$ & $750^{*}$ & $200^{\dagger}$ & $200^{\dagger}$ & $200^{\dagger}$ \\
\hline Treatment & $1200^{\ddagger}$ & $2250 \S$ & $1200^{\ddagger}$ & $1200^{\ddagger}$ & $2250 \S$ \\
\hline Other care & Same & Same & Same & Same & Same \\
\hline $\begin{array}{l}\text { Total (excluding } \\
\text { other services) }\end{array}$ & 2700 & 3750 & 2150 & 1600 & 2650 \\
\hline
\end{tabular}

${ }^{\star}$ Estimated direct price of a night laboratory service including physician fee (from Capital Health Authority, Edmonton, Alberta); ${ }^{\dagger}$ Estimated price of home diagnosis including physician fee (from Canadian Liquid Air, Alberta); †Estimated price of a continuous positive airway pressure (CPAP) machine plus mask and tubing (cost in Edmonton); §Estimated price of an autotitrating CPAP (APAP) machine plus mask and tubing (cost in Edmonton)

Costs of therapy per patient in the APAP group were Euro1,264 \pm 352 versus Euro1,720 \pm 455 for the constant pressure group. A limitation of this analysis is that the same device was used for both groups of patients, whereas a more realistic comparison would have been between APAP and the use of a less-expensive conventional CPAP device for those whose treatment was initiated with a laboratory titration.

For the present analysis, the operating costs associated with the care of OSA were considered, including those for the diagnosis of the condition, titration for individuals who choose treatment with a positive airway pressure machine and the purchase price of the machine along with mask and tubing. Costs of treating comorbidities associated with the condition, additional physician consultations and maintenance costs are excluded. The machines (APAP and CPAP) are assumed to have equal efficacy, an assumption consistent with the literature.

The assumed cost categories of the analysis are shown in Table 3. Five scenarios were considered. First, the traditional mode of care was examined, which includes sleep laboratory diagnosis and titration, and treatment with a CPAP machine. This is the 'base-case' analysis. In the second scenario, diagnosis and titration occur in a sleep laboratory, but the patient purchases an APAP machine. In the third scenario, laboratory diagnosis, titration with an APAP machine in a home setting and purchase of a CPAP machine were assumed. In the fourth scenario, which was the least costly, diagnosis and titration occur in a home setting with APAP, and the patient purchases a CPAP machine. Lastly, in the fifth scenario, home diagnosis, home titration and treatment are all performed with an APAP machine.

An alternative approach in the first and second scenarios would involve the use of a split-night study, in which diagnosis and titration are concluded within a single night. Under the most favourable circumstances, total costs for each of these scenarios would be reduced by $\$ 750$. At a total cost of $\$ 1950$, the first scenario would become the least expensive of the options in which a sleep laboratory is used; however, it would still be more costly than the fourth scenario.

These estimates indicate that in some scenarios, APAP offers cost advantages in both diagnosis and titration. As expected, treatment with APAP is more expensive than treatment with CPAP; however, the costs of diagnosing OSA using APAP at home are likely markedly underestimated because they assume that this approach is as accurate as a laboratory diagnosis, and that additional studies will not have to be undertaken.

\section{DISCUSSION}

APAP devices provide a further option in the management of OSA. Considering the present review, it appears that there is potential for the use of this technology; however, its effectiveness in routine health care has not yet been established. The studies we located essentially addressed the efficacy of APAP when used for different applications, usually evaluating patient populations that did not include individuals with congestive heart failure, obstructive respiratory disorders, high upper airway resistance syndrome or those who had a substantial amount of central apnea. These findings are consistent with those of an American Academy of Sleep Medicine review by Berry et al (38). Although the issue of APAP use is complicated by the variety of devices on the market, rather similar results were obtained with the different devices.

There was little information on the use of APAP in diagnosing OSA from the controlled studies that were identified. Further research on this application is needed using studies with stronger methodology and larger numbers of subjects. Attention must be given to validation in specific clinical settings because there is no evidence available on the efficacy of APAP in this application outside a sleep laboratory setting. There are potential hazards as well, including missed diagnoses such as high upper airway resistance syndrome, and risks for patients with comorbidities such as severe desaturation and potential cardiac events. The comparative studies excluded patients with these potentially confounding diagnoses and we suggest that APAP should not be used in these settings.

APAP is promising for use in titration, with a number of comparative studies showing that treatment pressures estimated using this approach were either similar to or lower than those derived using manual titration; there were no adverse physiological effects. These findings, however, must be qualified by the exclusion of patients with various serious medical conditions in a number of studies, and the use of attended titration in most cases. In a number of patients, interventions were necessary during attended APAP titration to stop mask leaks, adjust mask fit or provide supplemental oxygen for nocturnal hypoxemia.

In the studies on the treatment of OSA, APAP allowed use of lower treatment pressure than CPAP but this was not necessarily associated with an increased use of the device, and no study found any statistically significant difference in clinical 
outcomes between APAP and CPAP. These findings are consistent with those reported by Ayas et al (39), who provided pooled estimates of AHI, ESS and mean applied pressure from nine trials. Had statistically significant differences been found, they would not necessarily have been of any clinical significance. There were indications from poorly described surveys of some patient preference for APAP.

Most patients in the studies had already had a formal sleep study and some had a conventional CPAP titration or were being treated with CPAP before they were first treated with APAP. The results in such patients may differ from those of naïve, untreated patients (11). The performance of APAP under routine conditions, in home use and in a general population of patients with moderate-to-severe OSA is still unclear.

Long-term CPAP compliance is related to the first-night experience with this treatment modality (40). The patients' initial experiences with CPAP treatment may be a crucial factor in determining their subsequent regular use of CPAP, and any changes in the method of titration must include compliance as a long-term outcome.

Since the conclusion of the present review, further randomized crossover studies have reported similar findings, with APAP giving similar outcomes to CPAP in different patient groups. These included patients with a high within-night variability in pressure requirements (41), and patients with difficult-to-treat OSA (where the comparator was bilevel CPAP) (42).

Variability in the efficacy of different devices has also received further attention. Kessler et al (43) found that two types of APAP devices (AutoSet [ResMed, Australia] and Somnosmart [Weinmann, Germany]) predicted significantly different therapeutic pressures for fixed CPAP therapy. They concluded that unattended APAP titration during one night of hospital stay cannot be used to accurately determine the therapeutic CPAP. Considerable differences in the efficacy of the three devices (AutoSet, Horizon [DeVilbiss, Germany] and Virtuoso [Respironics, USA]) were reported by Stammnitz et al (44). However, another study (45) found that two types of APAP devices (DeVilbiss AutoAdjust LT and AutoSet T) were equally effective as fixed-pressure CPAP.

We suggest that caution is still required in the use of APAP, and that the limited evidence of useful clinical performance and potential cost savings need to be supplemented by further studies on its cost and effectiveness.

ACKNOWLEDGEMENTS: This study was supported by the Canadian Coordinating Office for Health Technology Assessment. Further details are available in an earlier version of this review <http://www.ccohta.ca>.

\section{REFERENCES}

1. Jenkinson C, Davies RJ, Mullins R, Stradling JR. Comparison of therapeutic and subtherapeutic nasal continuous positive airway pressure for obstructive sleep apnoea: A randomised prospective parallel trial. Lancet 1999;353:2100-5.

2. Huang X, Xiao Y, Zou D. [Auto CPAP Set system for diagnosis and therapy of sleep breathing disorders]. Zhonghua Jie He He Hu Xi Za Zhi 1998;21:468-70.

3. Gugger M. Comparison of ResMed AutoSet (version 3.03) with polysomnography in the diagnosis of the sleep apnoea/hypopnoea syndrome. Eur Respir J 1997;10:587-91.

4. Gugger M, Mathis J, Bassetti C. Accuracy of an intelligent CPAP machine with in-built diagnostic abilities in detecting apnoeas: A comparison with polysomnography. Thorax 1995;50:1199-201.

5. Randerath W, Parys K, Lehmann D, Sanner B, Feldmeyer F, Rühle KH. Self-adjusting continuous positive airway pressure therapy based on the measurement of impedance: A comparison of free pressure variation and individually fixed higher minimum pressure. Respiration 2000;67:272-9.

6. Randerath WJ, Parys K, Feldmeyer F, Sanner B, Ruhle KH. Self-adjusting nasal continuous positive airway pressure therapy based on measurement of impedance: A comparison of two different maximum pressure levels. Chest 1999;116:991-9.

7. Randerath WJ, Buscher L, Gil G, Domanski U, Ruhle KH. Automatical nCPAP therapy based on the forced oscillation

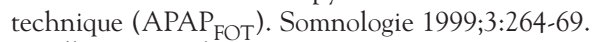

8. Stradling JR, Barbour C, Pitson DJ, Davies RJ. Automatic nasal continuous positive airway pressure titration in the laboratory: Patient outcomes. Thorax 1997;52:72-5.

9. Lloberes P, Ballester E, Montserrat JM, et al. Comparison of manual and automatic CPAP titration in patients with sleep apnea/hypopnea syndrome. Am J Respir Crit Care Med 1996;154:1755-8.

10. Teschler H, Farhat AA, Exner V, Konietzko N, Berthon-Jones M. AutoSet nasal CPAP titration: Constancy of pressure, compliance and effectiveness at 8 month follow-up. Eur Respir J 1997;10:2073-8.

11. Teschler H, Berthon-Jones M, Thompson AB, Henkel A, Henry J, Konietzko N. Automated continuous positive airway pressure titration for obstructive sleep apnea syndrome. Am J Respir Crit Care Med 1996;154:734-40.

12. Berkani M, Lofaso F, Chouaid C, et al. CPAP titration by an autoCPAP device based on snoring detection: A clinical trial and economic considerations. Eur Respir J 1998;12:759-63.
13. Sériès F. Accuracy of an unattended home CPAP titration in the treatment of obstructive sleep apnea. Am J Respir Crit Care Med 2000;162:94-7.

14. Sériès F, Marc I. Efficacy of automatic continuous positive airway pressure therapy that uses an estimated required pressure in the treatment of the obstructive sleep apnea syndrome. Ann Intern Med 1997;127:588-95.

15. Ficker JH, Clarenbach CF, Neukirchner C, et al. Auto-CPAP therapy based on the forced oscillation technique. Biomed Tech (Berl) 2003;48:68-72.

16. Randerath WJ, David M, Feldmeyer F, Galetke W, Ruhle KH. Automatic CPAP based on impedance - comparison of constant CPAP with an individual pressure range. Somnologie 2001;5:121-5.

17. Randerath WJ, Galetke W, David M, Siebrecht H, Sanner B, Ruhle K. Prospective randomized comparison of impedancecontrolled auto-continuous positive airway pressure (APAP(FOT)) with constant CPAP. Sleep Med 2001;2:115-24.

18. Ficker JH, Fuchs FS, Wiest GH, Asshoff G, Schmelzer AH, Hahn EG. An auto-continuous positive airway pressure device controlled exclusively by the forced oscillation technique. Eur Respir J 2000;16:914-20.

19. Miyazaki S, Itasaka Y, Ishikawa K, Togawa K. Evaluation of the auto continuous positive airway pressure efficacy by upper airway pressure measurement. Psychiatry Clin Neurosci 1999;53:327-9.

20. Garcia Arroyo I, Terán Santos J, Cordero Guevara J,

Rodriguez Pascual L. [Efficacy of demand of positive airway pressure therapy for treating obstructive sleep apnea syndrome]. Arch Bronconeumol 1999;35:208-13.

21. Behbehani K, Yen FC, Lucas EA, Burk JR. A sleep laboratory evaluation of an automatic positive airway pressure system for treatment of obstructive sleep apnea. Sleep 1998;21:485-91.

22. Plywaczewski R, Zgierska A, Bednarek M, Zielinski J. [Comparison of automatic (AUTO-CPAP)and "manual" CPAP pressure titration in patients with obstructive sleep apnea]. Pneumonol Alergol Pol 2000;68:232-7.

23. Ficker JH, Wiest GH, Lehnert G, Wiest B, Hahn EG. Evaluation of an auto-CPAP device for treatment of obstructive sleep apnoea. Thorax 1998;53:643-8.

24. Ficker JH, Wiest GH, Lehnert G, Fischer CJ, Katalinic A, Hahn EG. [Auto-CPAP treatment in obstructive sleep apnea syndrome: A prospective randomized study during initiation of treatment]. Dtsch Med Wochenschr 1997;122:1482-8. 
25. Hoster M, Schlenker E, Ruhle KH. [Computer-assisted nCPAP settings in comparison with conventional methods]. Pneumologie 1997;51(Suppl 3):754-7.

26. Hoster M, Schlenker E, Ruhle KH. [Effect of automatically titrated CPAP systems on sleep and respiration in sleep apnea syndrome]. Wien Med Wochenschr 1996;146:385-7.

27. Scharf MB, Brannen DE, McDannold MD, Berkowitz DV. Computerized adjustable versus fixed NCPAP treatment of obstructive sleep apnea. Sleep 1996;19:491-6.

28. Sharma S, Wali S, Pouliot Z, Peters M, Neufeld H, Kryger M. Treatment of obstructive sleep apnea with a self-titrating continuous positive airway pressure (CPAP) system. Sleep 1996;19:497-501.

29. Planes C, D'Ortho MP, Foucher A, et al. Efficacy and cost of home-initiated auto-nCPAP versus conventional nCPAP. Sleep 2003;26:156-60.

30. Massie CA, McArdle N, Hart RW, et al. Comparison between automatic and fixed positive airway pressure therapy in the home. Am J Respir Crit Care Med 2003;167:20-3.

31. Randerath WJ, Schraeder O, Galetke W, Feldmeyer F, Ruhle KH. Autoadjusting CPAP therapy based on impedance efficacy, compliance and acceptance. Am J Respir Crit Care Med 2001;163:652-7.

32. Sériès F, Marc I. Importance of sleep stage- and body positiondependence of sleep apnoea in determining benefits to auto-CPAP therapy. Eur Respir J 2001;18:170-5.

33. d'Ortho MP, Grillier-Lanoir V, Levy P, et al. Constant vs automatic continuous positive airway pressure therapy: Home evaluation. Chest 2000;118:1010-7.

34. Hudgel DW, Fung C. A long-term randomized, cross-over comparison of auto-titrating and standard nasal continuous airway pressure. Sleep 2000;23:645-8.

35. Teschler H, Wessendorf TE, Farhat AA, Konietzko N, Berthon-Jones $\mathrm{M}$. Two months auto-adjusting versus conventional nCPAP for obstructive sleep apnoea syndrome. Eur Respir J 2000;15:990-5.
36. Konermann M, Sanner BM, Vyleta M, et al. Use of conventional and self-adjusting nasal continuous positive airway pressure for treatment of severe obstructive sleep apnea syndrome: A comparative study. Chest 1998;113:714-8.

37. Meurice JC, Marc I, Sériès F. Efficacy of auto-CPAP in the treatment of obstructive sleep apnea/hypopnea syndrome. Am J Respir Crit Care Med 1996;153:794-8.

38. Berry RB, Parish JM, Hartse KM. The use of auto-titrating continuous positive airway pressure for treatment of adult obstructive sleep apnea. An American Academy of Sleep Medicine review. Sleep 2002;25:148-73.

39. Ayas NT, Patel SR, Malhotra A, et al. Auto-titrating versus standard continuous positive airway pressure for the treatment of obstructive sleep apnea: Results of a meta-analysis. Sleep 2004;27:249-53.

40. Drake CL, Day R, Hudgel D, et al. Sleep during titration predicts continuous positive airway pressure compliance. Sleep 2003;26:308-11.

41. Noseda A, Kempenaers C, Kerkhofs M, Braun S, Linkowski P, Jann E. Constant vs auto-continuous positive airway pressure in patients with sleep apnea hypopnea syndrome and a high variability in pressure requirement. Chest 2004;126:31-7.

42. Randerath WJ, Galetke W, Ruhle KH. Auto-adjusting CPAP based on impedance versus bilevel pressure in difficult-to-treat sleep apnea syndrome: A prospective randomized crossover study. Med Sci Monit 2003;9:CR353-8.

43. Kessler R, Weitzenblum E, Chaouat A, Iamandi C, Alliotte T. Evaluation of unattended automated titration to determine therapeutic continuous positive airway pressure in patients with obstructive sleep apnea. Chest 2003;123:704-10.

44. Stammnitz A, Jerrentrup A, Penzel T, Peter JH, Vogelmeier C, Becker HF. Automatic CPAP titration with different self-setting devices in patients with obstructive sleep apnoea. Eur Respir J 2004;24:273-8.

45. Senn O, Brack T, Matthews F, Russi EW, Bloch KE. Randomized short-term trial of two autoCPAP devices versus fixed continuous positive airway pressure for the treatment of sleep apnea. Am J Respir Crit Care Med 2003;168:1506-11. 


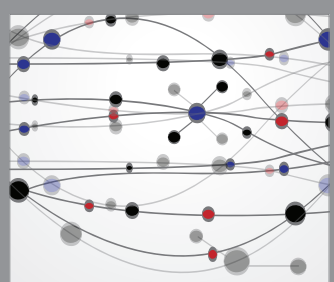

The Scientific World Journal
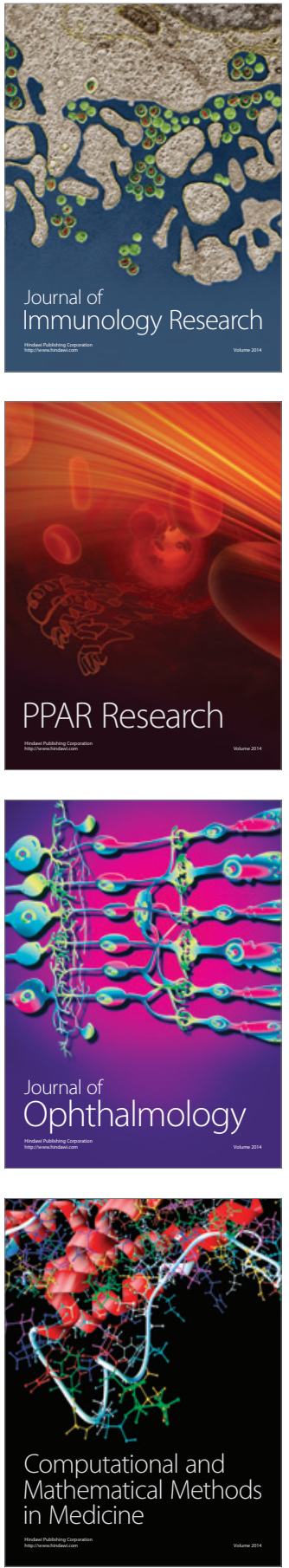

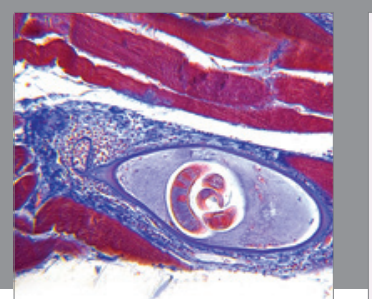

Gastroenterology Research and Practice

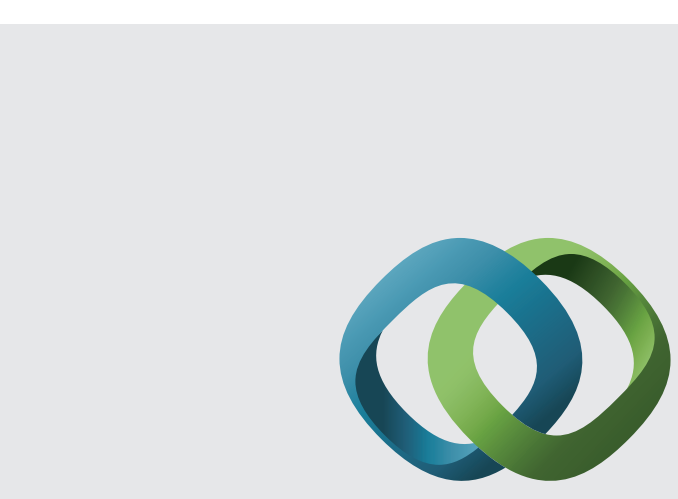

\section{Hindawi}

Submit your manuscripts at

http://www.hindawi.com
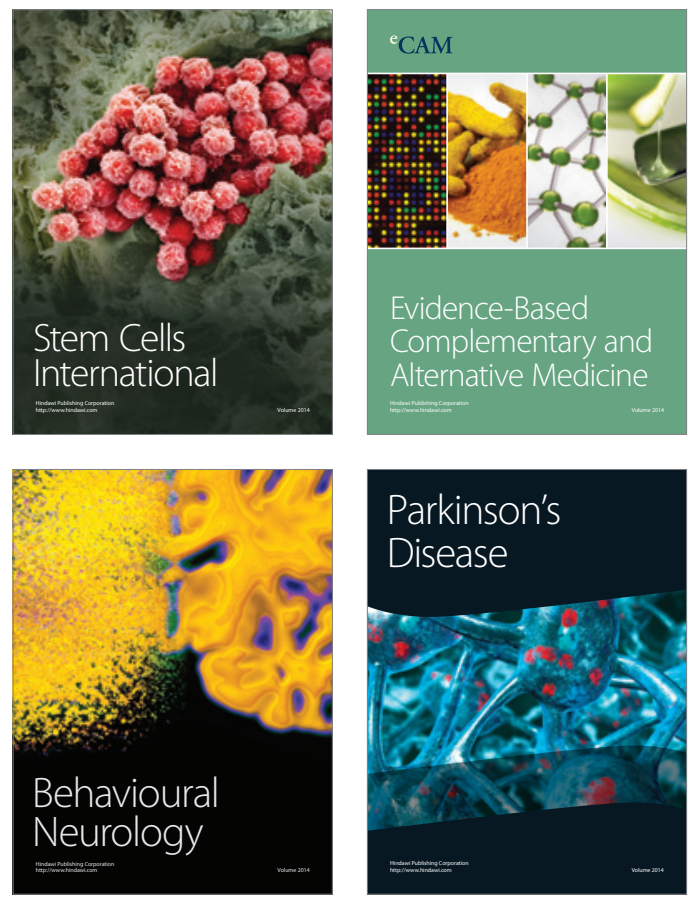
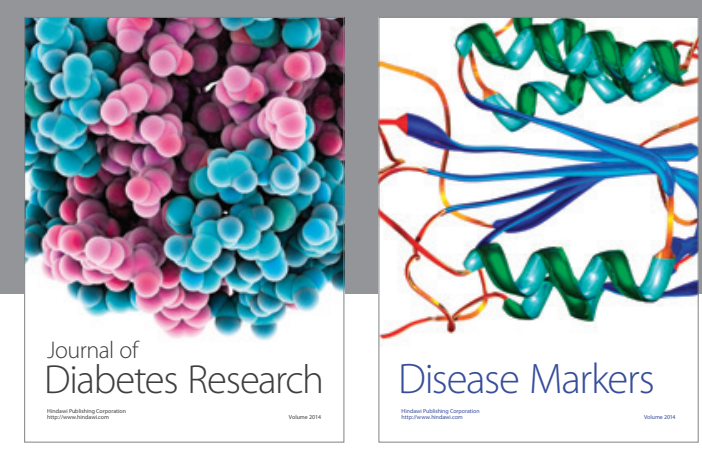

Disease Markers
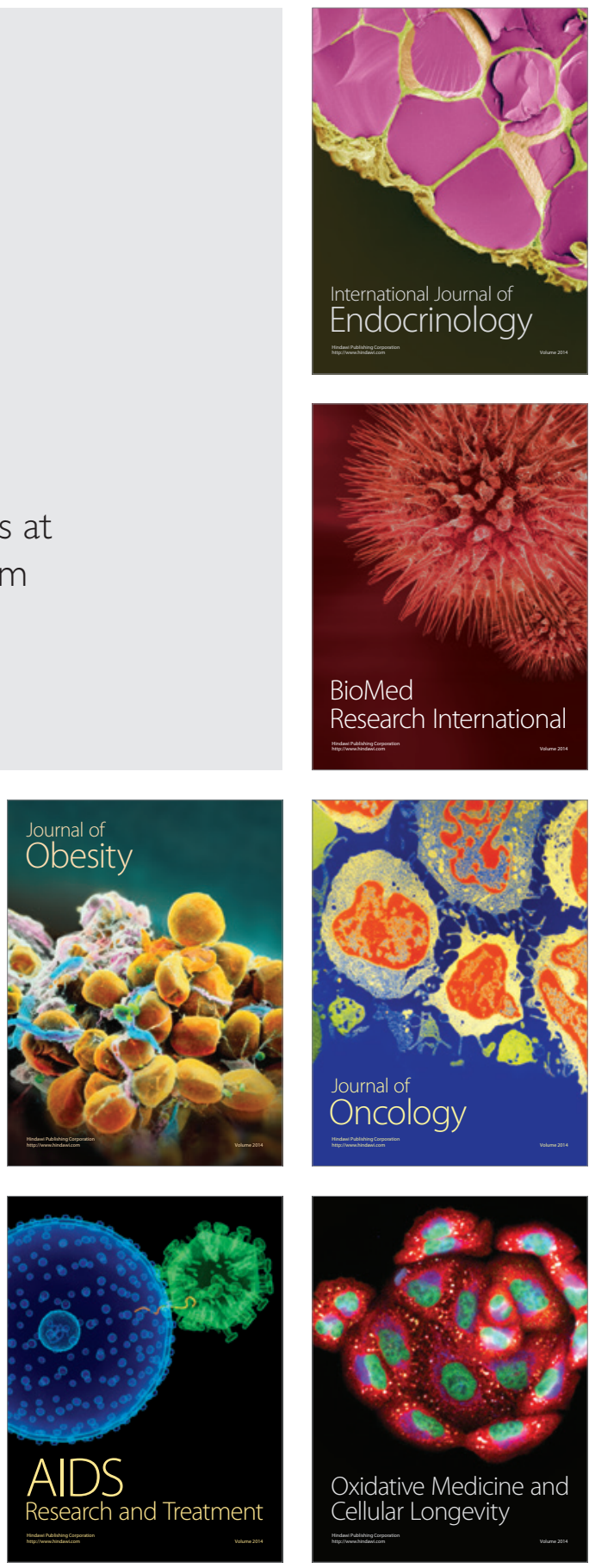